\title{
A critical perspective on Integrated Project Delivery (IPD) applied in a Norwegian public hospital project
}

\author{
Bo Terje K alsaas ${ }^{1 *}$, Una Obiose $\mathrm{K}$ riston N wajei ${ }^{1}$, and Christine Bydall ${ }^{1}$ \\ ${ }^{1}$ Department of Engineering Sciences, University of A gder, J on Lilletunsvei 9., Grimstad, Norway
}

\begin{abstract}
Does the IPD concept deliver as required and expected, and if not, how can that be explained? This paper is a critical realist inspired methodology based on a combination of the inductive and deductive approaches used in case study research. IPD is based on relational contracting between multiple parties, in this case between the Owner, Contractor, M EP subcontractors and a group of Consulting engineers who share control of the project. At the core of the concept is shared risk and opportunities among the parties in the IPD contract. Our theoretical perspectives are based mainly on the Principal-Agent theory (PA), Transaction Cost theory (TC), and its related incentives. This paper reports on a study of the development of an existing public hospital that is constructing first a psychiatry and then a somatic building. The data collection in the paper is mainly in connection with the construction of the psychiatry building in 2018. O ur findings show that IPD represents a gamechanger in the behaviours and the organizing of AEC (A rchitect-EngineerConstruction) projects, ex-post IPD-contract. We identify examples of swapping occurring that require deep collaboration, which stems from changes in the commercial incentives. However, different individual incentives coupled with accompanying mindsets and opportunistic behaviour are still part of everyday life and are linked to people@ past experiences, which can be understood as contextual conditions. In addition, the decision-making processes were not effective and characterized by revisiting previous decisions.
\end{abstract}

Keywords: AEC-industry, alignment of interests, commercial and individual incentives, IPD, public procurement

\section{Introduction}

Many challenges have been registered in construction (AEC) projects within what one designates conventional project delivery models, Design-Bid-Build (DBB) or Design-Build (DB). There are challenges that are especially related to the delivery of quality and customer value, and the industry is characterized by relatively low-profit margins.

* Corresponding author: bo.t.kalsaas@uia.no 
There are challenges that are especially related to a high level of conflict, limited innovation and that the industry is characterized by relatively low-profit margins [1]. It is also been argued that the industry has lower productivity growth than other industries [1]. The DB form appears to be replacing DBB as the preferred project delivery model. This is very common within the Norwegian construction (industry) and can be seen in the transition from DBB to DB regarding the construction of infrastructure projects [2].

Projects are usually carried out by many companies that specialize in branches of design, and different fields of construction, all having their own business model. In order to align commercial interests and goals, one needs a shared business model for the whole project. Furthermore, there is a trend for construction projects to become more technical in relation to automation and technology (e.g. smart buildings), which means that projects increase in complexity and require more collaboration to solve interdependencies.

In Norway, there are changes in the choice of project delivery model. There is a debate surrounding traditional models as they are characterized as models that often lead to conflict and dispute. One example of this is a meeting ${ }^{\dagger}$ where it was argued from a lawyer's point of view that the Norwegian Standard (NS) for contracts regarding DBB and DB has few common incentives and is more a cause for problems than solving problems.

In the Lean Construction (LC) environment in the US, there has been interest in a type of delivery model denoted Integrated Project Delivery (IPD) which is characterized as a game-changer [3]. Thus, multiple party contracts are introduced with risk and opportunity sharing, which is expected to change the direction of the parties' incentives in relation to working together without any hidden agendas by the alignment of their interests. The theoretical foundation lies within the LC-triangle [4, 5] which looks at the importance of fine-tuning the parties in relation to commercial interests, organization and production. Our research interest is to contribute by critically highlighting the potential that lies within IPD in improving project execution. We will do this by studying an IPD-project located in Norway, the Tønsberg project, which is in the process of building new psychiatric and somatic wards. The data in the study is mainly collected from the creation of the psychiatric building which is built before the somatic part. The paper builds upon and is the development of a master thesis by Nwajei and Bydall [6].

In the next section, the methodology used will be described and then we will examine the theoretical aspects related to understanding behaviour in construction projects. The IPD concept is further explained, including how incentives change. Three propositions have been developed that are further substantiated then an empirical analysis is carried out of the propositions and finalized with a conclusion.

\section{The IPD concept}

Integrated Project Delivery (IPD) according to Lahdenperä [7] has been an emerging method from North America that originated from Japan, labelled as "gentlemanly principles". This concept has its origins in Lean and the Toyota Production Systems (TPS) where adversarial supplier relationships were transformed into cooperative relationships ${ }^{\ddagger}$.

IPD is considered to have started in 2005 with the aim of aligning the commercial incentives of project participants in the AEC industry [8-9]. In the US, the Lean Construction environment tried to address the challenges in the construction industry, by defining an integrated process. The result of this was the five "big ideas" summarized as collaboration; relationships; networks of commitments; optimization; and, the pairing of learning with action [3]. Several projects adopted IPD and put it into practice [9].

$\uparrow$ Seminar at DLA Piper, M arch 13th, 2018

$\$$ Further information can be found in cases of J aguar and Nippondenso and the Sutter Health project [3]. 
It was not until 2014 that the IPD-principles were defined as continuous involvement of the owner, key designers and contractors from early design through to project completion: shared risk and reward; joint project control; limited liability; and, a multi-party agreement or equal interlocking agreements. Without building on those principles, projects could not really be described as IPD (op cit.). The IPD concept consists of collaboration and coordination which can be realised by the solution of fusing the core organizations under a single agreement- integrated to work together and share ideas [10].

In an IPD, collaboration occurs early, whereby the constructors are present from the onset. They are part of the team and the team are not just focused on their own speciality. Knowledge and expertise are no longer hoarded [11]. The group make progress together, as they are aware of risks and rewards, not just their own but for others. IPD has been described as a game-changer in the way projects have been delivered. In the US, projects using all these principles have been successful, as no litigation has ensued as a result [11].

Do et al. [8] also argues that there is a close connection between IPD and the Target Value Design (TVD) concept [12], which was introduced in 2004. The American Institute of Architects [13] describes TVD as a unique way of creating value within budgeted constraints by designing to a financial target, using several iterations, rather than estimating a pre-decided detailed design. Designing to targets allows changes to occur, that normally would be regarded as an extra cost. Through combining IPD and TVD the commercial incentives are aligned towards the project's goals which are reflected in achieving customer value. It is no longer about completing unilateral contributions at the least cost. Thus, the commercial incentives move to re-aligning the thinking of participants from short term objectives to optimization and improvement of the whole product. In this paper, we study the impact of IPD in different aspects of collaboration in relation to the preservation of the parties' interests in the Tønsberg project.

\section{Method}

This research deals with a single project and the most obvious research approach to choose is case study methodology. In this instance our first approach was to look to [14] concerning critical realism (theoretically informed) case studies, then supplement this with Yin [15] using the case study method.

In line with critical realism thinking, we seek to identify mechanisms that have the potential to produce certain results, which we entitle propositions [15]. Incentives are something that motivates people into action, and that might affect behaviour and choices by making one alternative preferable than another. We consider incentives as a structure that together with mechanisms can lead to certain outcomes, given certain conditions [14]. Conditions can be identified through contextual analysis. It is a part of our method to compare our findings with incentives in traditional project delivery models. We focus on commercial incentives where rewards can come in the form of financial gains, but also on the internal and individual incentives which might be in the form of satisfaction or pleasure in the action or activity one has performed [16].

Qualitative data collection was done through conducting fourteen interviews, of which five are with the client, five with the main contractor (design management and production) of which one is an electro subcontractor and four are with the project consultants (design management). In addition, quantitative data were collected from 18 survey participants. 10 of those participants were from the client, 7 were from the main contractor and 1 was a subcontractor. The data were mainly gathered from the the psychiatry building in 2018 . 


\section{Theoretical perspectives}

When analysing relationships between companies and organizations in construction projects, it is relevant to first think of the principal-agent theory [17], that analyses the contractual challenges confronting business partners under conditions of information asymmetry, which is a typical situation at the beginning of a buyer-supplier relationship. Information asymmetry has the potential to lead to opportunism, defined as self-interest seeking with guile [18]. Schauwecker [19] in [20], lists the following types of opportunistic behaviours by suppliers: unpunctual delivery, quality deficits, poor service, overcharged prices for spares and additions, limited commitment to problem-solving, and the manipulation of markets through the bribing of purchasers. Moreover, opportunism can include cheating, breach of contract, stealing, distortion of data, dishonesty, false threats and promises, misrepresentation, and withholding information [18, 21-23]. However, when we examine the AEC-industry in a Norwegian context, we recognize again several aspects, such as late delivery, overcharged prices for addenda and quality deficits. According to Lai et al. [24], opportunism represents purely selfish behaviour, whereby one ignores the consequences for the other actors.

Related to bounded rationality, a contract may only include the conditions that the principal is able to predict in advance, which in turn gives rise to an incomplete contract, and the agent gets the possibility to act opportunistically after the contract is signed [25]. The risk of opportunism is, to a large extent, the driving force behind contractual control mechanisms in business relationships [26].

A challenge for the buyer is to realise an important potential capacity of transactions, that supplier commitment and trust may evolve over time. An important distinction can be made between before (ex-ante) and after (ex-post) contractual conclusion, and it is here that Steinle et al. [20] expands on agency theory by showing that not only do ex-post forms of opportunism but also ex-ante forms can lead to moral hazard which can be understood as opportunistic behaviour after contracting.

Opportunism is also a central aspect in transaction cost theory [18], which in relation to principal-agent theory is since humans have bounded rationality and are seeking self-interest. This means that if individuals are presented with the opportunity to maximize their utility, they will behave opportunistically, which leads to a rise in transaction costs. A central difference between these two theories is that agency theory has an ex-ante contractual focus i.e. alignment of interests, while transaction cost theory addresses ex-post governance structure [27]. Transaction cost theory focuses more on minimising ex-post transaction costs, while principal-agent theory aims at minimizing these same costs, but with an ex-ante alignment of incentives [28].

We understand opportunism explained earlier in principal-agent theory and transaction cost theory as opportunism based on commercial incentives. When [8] discuss the challenges in misalignment of commercial incentives on IPD and TVD projects, they are discussing the same phenomenon, even though they do not use our theoretical basis. They base their article on experiences from six IPD projects and a practical brainstorming of ideas of potential misalignments, which in our understanding is found in opportunistic behaviour based on various commercial interests. Opportunistic behaviour, however, is a broader term that is not only related to commercial incentives which we will elaborate below.

Luo [29] and Masten [30] distinguish between strong and weak opportunism, where strong opportunism violates unwritten but understood relational norms. Relational norms can be understood as "expectations about behaviour that at least partially is shared by a group of decisions makers" (Steinle et al. [19] p. 127).

Muris [31] operates with a different distinction, subtle and blatant opportunism. While subtle is difficult to detect and could be masked as legitimate conduct, blatant is defined 
as an obvious attempt to act opportunistically. Uncertainty occurs in a lot in AEC-projects and is furthermore a driver for opportunistic behaviour [18].

In theory and practice, however, the mechanisms of governance and incentives to regulate inter-organizational behaviour do not find universal support. Several scholars have criticised the theoretical grounds for opportunistic behaviour in business relationships. In his vast examination of contracts, Macneil [32] distinguishes between transactional and relational contracts, where the latter puts more emphasis on trust rather than monitoring mechanisms. IPD is an example of relational contracting.

\section{The Case}

The Tønsberg project (TP) is the first to introduce an Integrated Project Delivery (IPD) model in a Norwegian context $[33,34]$. TP is in the seventh stage of a renewal process of the Hospital in Vestfold- Tønsberg, which started in 2015 and is planned to finish in 2021. The remaining stages consist of two new buildings; psychiatry (which is studied) and somatic. Handover dates for these buildings are in 2019 and 2021, respectively. The Tønsberg project has an estimated price of ca. 2.7 billion NOK. The project organization consists of three parties; The Hospital in Vestfold ( $\mathrm{SiV}$ ) representatives, entrepreneur organization (Skanska UK \& Norway) and an alliance of consultants (CURA). The owner procured the consultants and the contractor alliances in parallel. The owner considered DB as a starting point with the strategy of later transforming DB to IPD. That is why the owner procured consultants individually to avoid traditional DB relationships between the contractors and the consultants. During the competitive procurement process, there were ten bids from consultant groups and three from contractor alliances. The owner had developed a sketch project as part of the basis for the competition. When evaluating the different bids, the owner weighted 20 per cent on price, 40 per cent on task understanding and how they intended to conduct an IPD and the last 40 per cent was on competence.

The consulting alliance selected is an amalgamation of six companies, under the group name CURA. The contractor alliance is made up of the main contractor and three technical subcontractors. Contractors and consultants signed a Memorandum of Understanding, as a document attachment to the DB contract, which showed a joint intention to use IPD as the project delivery model. The consultant group was contracted based on an hourly rate, while the contractor had a price per square meter and a mark-up.

With guidance from an American attorney (and one attorney representing each party), they set up an IPD contract customized to conform to Norwegian laws on public procurement, which was adapted according to the EU regulations on the same topic. The project's goals given by the owner were to build fifty per cent faster by using a high degree of industrialisation and prefabrication, to be ten per cent cheaper and improve customer quality better than similarly comparable projects. In addition, to apply IPD as a procurement strategy to reach the goals, advanced BIM and lean construction methods were introduced for design and production management.

\subsection{The IPD arrangement in the Tønsberg project}

The Tønsberg project has a compensation model for the parties involved in the IPD, a simplified version is illustrated in Figure 1. This figure shows four different scenarios (each represented by a column), where the top line represents the owner's cost, the lower line the target cost and the difference between owner's and target cost represent the profit in the left column. The first scenario and point of departure illustrate the profit when the project reaches the target cost. Scenario two shows what happens if they go over the target cost; they eat into their profit. If they can lower their target cost (e.g. coming up with better solutions), then the 
owner's cost goes down as well, and they increase the profit as illustrated in scenario three. The worst case is represented in the fourth column. That is the case where the owner's cost is exceeded, and the actors will have to give up their profit, however, the owner covers the additional cost. Risks and opportunities (reward) lie in the target cost segment.

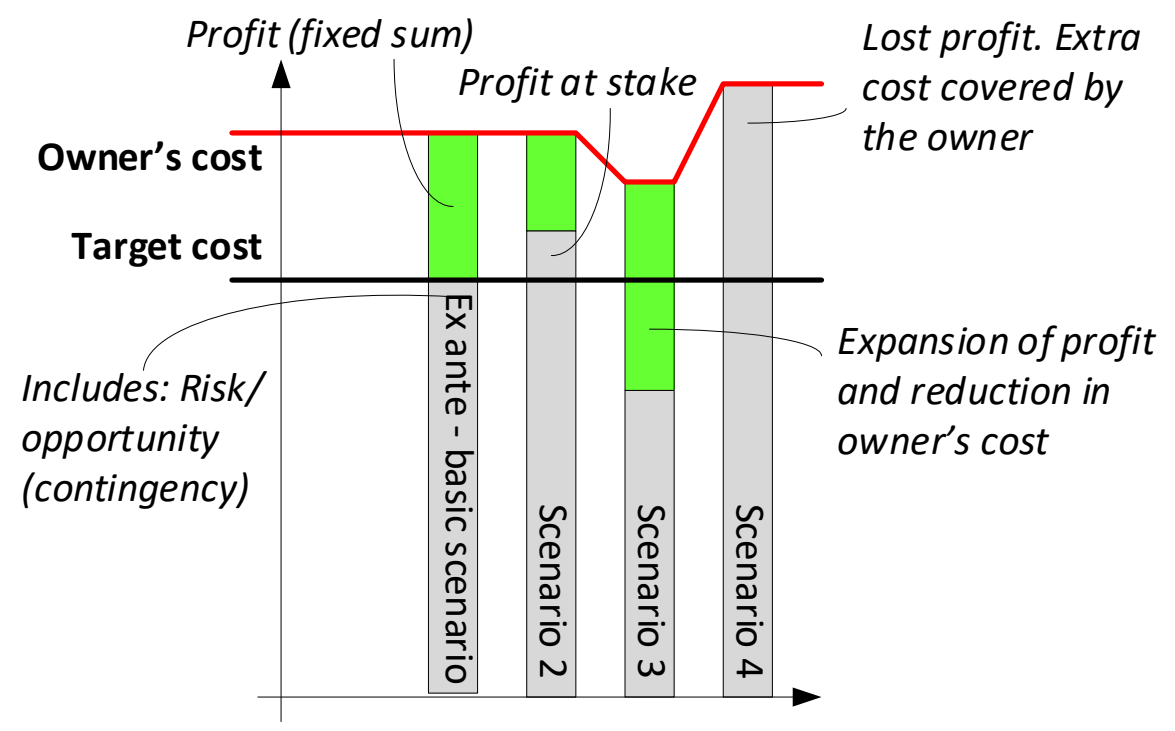

Figure 1. Illustration of the compensation model for IPD in the Tønsberg project [34]

Comparing the IPD arrangement in the Tønsberg project to the literature on IPD, there are similarities that confirm that this project is an IPD project. Firstly, when looking at the project principles, the Tønsberg project is consistent with four of the five principles stated in the latest version of the AiA guide [10]. The project applies interlocking contracts, joint decision making, shared risk and reward and continuous involvement from the owner. However, the project does not have limited liability among project participants instead it limits the use of compensation clauses in the contract for delays and changes [35]. Secondly, the use of mirrored interlocking contracts and the formation of the players is consistent with AiA guide [13] whereby projects should have IPD key and IPD supporting players. However, the conversion from a Design-Build (DB) to an IPD is unstipulated in the literature except for Ashcraft [36] in the owner's guide whereby he explains the challenges participants have felt going over from a DB to an IPD.

\subsection{Theoretical analysis and propositions}

Based on the description of the IPD approach in the Tønsberg project and the theoretical perspectives discussed earlier the following research question was formulated: Is IPD a game-changer that leads to alignment of incentives and interests? We answer the research question by testing whether we can verify it using three propositions [15], cf. Table 1. The mechanisms identified in the right-hand column are built on the thinking around economic incentives, cf. the theoretical perspectives. Mechanisms have the potential to produce what we denote as propositions. Different conditions, however, may cause the result not to be confirmed. The effort has been made to define such conditions in the contextual analysis. 
Shared risk and reward mean that even though people are self-seeking-interest creatures in behaviour, the economic incentives are designed to work in such a way that no one wins if good ideas are held back to increase sales later, as all are sharing the profit. On the contrary, tactically holding back ideas could lead to lost opportunities. The incentives work in such a way that it becomes rationally best to think of what is best for the project, which is in stark contrast to sub-optimization and risk aversion. In terms of Principle Agent (PA), the IPD arrangement aligns the incentives and the interests of the IPD-involved parties where important sources of opportunistic behaviour and moral hazard is supposed to be removed. The same theoretical analysis can be applied to proposition 2, where a deepened form of collaboration occurs to include swapping of work tasks. However, there is expected to be space for ex-ante opportunism in the process of identifying the target price (Figure 1).

Table 1. Propositions and mechanisms for the study (ex-post IPD-contract)

\begin{tabular}{|c|c|c|}
\hline No & Proposition & Mechanism/commercial incentives \\
\hline 1 & $\begin{array}{c}\text { IPD provides less scope for sub-optimization } \\
\text { and opportunistic behaviour between } \\
\text { companies in the value chain }\end{array}$ & $\begin{array}{c}\text { Share risk and opportunities. Thus no one } \\
\text { has the commercial incentive to hold back } \\
\text { good suggestions or engage in risk } \\
\text { aversion }\end{array}$ \\
\hline 2 & $\begin{array}{c}\text { IPD provides better conditions for unified } \\
\text { solutions (swapping) than traditional } \\
\text { contracts }\end{array}$ & $\begin{array}{c}\text { Same mechanism as in the first } \\
\text { proposition, but where the mechanism } \\
\text { takes the collaboration a step further }\end{array}$ \\
\hline 3 & $\begin{array}{c}\text { IPD safeguards quality and customer value } \\
\text { in a better way than alternative } \\
\text { implementation models while maintaining } \\
\text { constructability }\end{array}$ & $\begin{array}{c}\text { The owner is involved in the management } \\
\text { of the project at the same level as the IPD- } \\
\text { contractors and the consultants }\end{array}$ \\
\hline
\end{tabular}

For proposition 3, the owner's participation is aligned with the other IPD partners which provide the opportunity to follow up on short and long-term interests (i.e. a building that is fit for its purpose in terms of design, operation, maintenance and energy consumption). The counterproductive incentives have disappeared from a DB whereby the owner has the incentive to lean back and avoid taking unwanted risks. In addition, the contractor has the incentives to not involve the owner in decisions related to quality and customer value. Yet in a DBB, the owner has the incentive to design and engineer a good product, but instances arise where the contractor can be opportunistic because he is not responsible for integrating design and production. Below we first address the process ex-ante contract before the propositions that belong to ex-post IPD-contract.

\subsection{Empirical analysis}

\section{Ex-ante IPD-contract}

In the predesign phase, it was worked on the basis of a DB-contract in parallel with the development of the IPD-contract for the execution phase. A learning point for the client is that the IPD-contract should be ready before contracting. Another central contextual issue for the project is that the target cost had to be reduced by $25 \%$ at the end of the predesign phase, otherwise the client would have terminated the project. The cost reduction was achieved by optimizing the project and by tough negotiations, according to the client. At this point, the focus was on target cost, less on target value delivery.

As addressed in theory it's found to be the difference between ex-ante contract and expost contract in the project. Data indicates that openness and trust have improved after the IPD-contract was signed. Moreover, is Target Value Delivery more in focus? The client, however, does accept some extra cost to smooth the system, which means that the target price 
increase. A learning point is moreover to put more weight on-boarding to the project from the client's part.

\section{Proposition 1}

The data shows that the Tønsberg project has removed several sources of opportunistic behaviour by establishing a common business model for the actors through the alignment of commercial incentives. As in projects organized as DB and IPD, the challenges are similar concerning the owner's decision-making, for example, delaying of decisions caused by the exposure to pressure from strong user groups. As a result of the delays, challenges have occurred in the choice of technical solutions which is not characterized as "blatant", but rather a "subtle" form of opportunism. The argument for a more expensive and better facility can perhaps be interpreted as being driven by commercial incentives. We can assume that they want to do what they think is best for their own work situation and for the owner, and so they have chosen to fight hard for these purposes.

This form of opportunism can also be seen in the different mindsets that exist between the designers and contractors, i.e. individual incentives and subtle opportunism in relation to a level of quality and cost, referring to the description of individual incentives in the method chapter. This problem is partially people dependant and forms a culture where decisionmaking is a rematch in discussions. In that context, it can be argued that designers search for the best possible solution while contractors focus on achieving the least possible costs. What we experience can also be based on old behaviours of thinking and acting found in traditional project delivery models where there is mistrust between the different discipline's intentions. The data confirms that the main contractor is reverting in his thinking back to a DB when it comes to the operations on site. The data also shows that the main contractor finds it frustrating not being able to control the designers as they would in a DB model.

A structural feature of the IPD is that the owner gets more leeway to demand work which might be difficult to identify from the participant's point of view as inclusive work or additional work. A representative from the consultant alliance explains the problem as: "The customer wants something evaluated and then you spend two days, then you show him, and he says; its good but it's too expensive, I do not want it! Now you have lost two days considering alternative solutions, scenarios and materials. You can claim compensation but it's difficult, while in a DB you would demand payment before taking this type of job".

However, this was not the case from the perspective of a respondent for the owner, who claims that resources are always set aside for calculation of alternative solutions in any form of project delivery model.

Some participants point out in the interviews that the psychiatry building has been a learning arena, and now they know each other, it is the belief that the somatic building will go much better.

\section{Proposition 2}

Swapping is a deepening of the collaboration between the actors, which is made possible by the commercial incentives of the IPD model, and the data confirms it took place. However, to make this work it is important that the actors understand the rationale behind IPD. Swapping is an example that the participating organizations have broken down important dividing lines between them and taken the variety of business models and replaced it by one common model addressing optimization of the project. 


\section{Proposition 3}

IPD has several aspects that are beneficial in safeguarding customer value through the fact that the owner is an equal partner throughout the implementation phase of the project. It requires a professional and proactive owner. The data indicates that the owner's building organization is not very much involved in making design decisions. However, this must be investigated further, as some part of the design work is very important for customer value.

The project is time-compressed regarding the psychiatry building, even though there are no penalties for late delivery, but the contractors and designers choose to go for an aggressive time schedule. An aggressive time schedule may be a risk in relation to enough involvement in the choice of solutions. Lack of penalties also has the potential to be beneficial in obtaining customer value, as carelessness and shortcuts in the end phases of construction projects can be avoided.

A critical activity from the owner's side is to define quality to a reasonable extent when calculating out the cost in order to reduce the extent of change requests, which may be stressful for collaboration when safeguarding customer value.

The data also shows that there was unanimous consensus about the challenging decisionmaking process which was characterized by many rounds of discussions involving slow and delayed decision making. A representative for the consultants describes it this way: "We have unclear lines as to who is making decisions, therefore we can we spend a lot of time discussing solutions, then someone else will say, no". Furthermore, informants for the technical consultants describe joint decision making as: "we are too many participants in the project meeting to handle details". In addition, respondents also gave examples of waste in the process as: "a decision is made orally; however, it is difficult to follow up because of an unclear organizational structure". Another example was: "Normally we go through several rounds to get to the solution with the contractor but once we get the nod, then it's okay. But here there will be a new round afterwards. It's the biggest challenge here I've seen". One respondent claimed that in a DB it is often very clear what to deliver: "either based on function or a half-described product", however, in IPD "it is challenging, you do not know where that list is".

Another statement, associated with power, addresses that there are: "different views, many more parties, many people, many who have opinions. It's a flat organization where the strongest party wins, and everyone has their good arguments". From a theoretical perspective, a flat organization means less hierarchy, and then we can expect less formal power and influence in that structure, however, individuals with a strong will can exert influence on that basis.

\section{Conclusions}

In the study, we have asked the question of whether IPD is a game-changer when it comes to an alignment of incentives and interests? The short answer is, yes when it comes to expost the IPD-contract, and less so the contract ex-ante. We find it important to distinguish between different types of incentives and interests because we find that what we perceive as commercial incentives have changed radically. Perhaps the best example of this practice is the swapping of resources across different budgets to achieve improved buildability and reduced cost. We are generally talking about a common business model for the Tønsberg project, and the alignment of commercial incentives work to some extent.

An exception may be found in the negotiations that occur between the constructors and the owner on the level of quality should be the basis for selecting solutions that support the budgeted target cost, where solutions are not always carefully specified. However, in relation 
to collaboration, the Tønsberg project exemplifies the potential of IPD as a framework for deeper collaboration in complex construction projects.

The project owner benefits from the IPD model by having a hand also on the steering wheel to ensure his short-term and long-term value-creating interests. In addition, the constructors have a good opportunity in the project to obtain an acceptable and predictable return. The model is also a game-changer when it comes to the distribution of power in the implementation phase compared to traditional DB projects. In the studied IPD-project, the main contractor must share power on equal terms with the owner, the designers and the MEP subcontractors. In addition, IPD gives better possibilities for communication as its commercial incentives encourage dialogue.

We see in the concept (structure) and in the underlying data that there may be a danger that the project owner pushes the designers and constructors too much regarding the economy in the project and with constantly demanding changes that can deteriorate the social environment and erode profits. If the IPD concept should work optimally, the owner must see his responsibility here. The data also shows that individual incentives and opportunistic behaviour play a role in forming mutual distrust between the contractors and the designers. This mistrust is often based on a different mindset and tensions in the trade-off between costs and well-designed technical and architectural solutions.

Based on our data, IPD provides at the least equally strong incentives to develop good constructible solutions which can be found in DB models. There is often a strong focus in the project to stay within, or preferably undergo, the target cost, to secure profits. Here the discussion is focused on the price of components, materials and designs of the simplest possible solutions. However, there is space for opportunistic behaviour from the contractors if quality has not been defined by the owner in the cost estimate. Nevertheless, the owner may choose higher quality solutions than those set out in the cost estimate if he makes more funds available.

Our research shows that the decision-making process was a challenge in the project, and this can be linked to the predominantly flat organisational structure stated by the informants who argue that many more people than usual are required to participate in the decisionmaking process. This has led to many rounds of discussions, which has particularly stressed the designers who argue that they must go through many more design iterations than they would normally be used to. Moreover, too many decisions have been sent up to the top management team, while the guiding principles state that decisions should be taken at the lowest possible level. The explanation given for these challenges was that mandates given had been unclear.

Like in traditional organized projects late client decisions were an issue and late delivery of drawings, but on the other hand, the designers argued that production started too early. These are issues we can relate to contextual factors. Contextual is also the stress imposed to the organisation that they in addition to the radical new IPD-contract they also had to adapt to new ways of working. Many new lean constructions inspired planning and management methods were introduced, and it was an aim to replace 2D-drawings with BIM and 3D. The reversed scheduling used in the Last Planner System collapsed during the construction of the psychiatry building, and 2D-drawings had to be used.

Furthermore, despite these factors, everyone was in unanimous agreement that productivity would increase in the design and construction of the somatic building. The reasoning for this unanimity was that the psychiatry building is seen as a learning arena, now that the players are familiar with each other and the decision-making process is becoming more efficient.

In relation to the methodology used, the approach in the use of critical realism has been fruitful with its distinction between structures, mechanisms and contexts. As we have stated earlier structures here are specifically the commercial incentives of the IPD. Furthermore, 
the nuances between different types of incentives are important in explaining and understanding the data collected. Commercial incentives are very important, however, there are also individual incentives and different mindsets that strongly affect the contextual environment.

\section{Future research}

In future research, there is a need to address IPD as a framework for innovation and learning. Important is also to study more closely the processes of identifying target prices in projects. To improve the validity of this case, research should also acquire more data that address other experiences from subcontractors and user groups. There is also a need for more information from actors who are outside the risk pool. In addition, more data needs to be collected from the survey and focus needs to be on providing an updated data set from the construction of the Somatic building, scheduled to be finished in 2021.

\section{Acknowledgements}

Thank you to the contract manager Bjørn Varegg who gave us access to study the Tønsberg project, and to him and all the others at the project from the client, the Cura Group, Skanska and MPEcontractors who openly have shared their experiences and perspectives. Also, thank you to Nye Veier AS who have contributed to financing our costs.

\section{References}

1. O.J. Klakegg, Byggenæring og gjennomføringsmodeller - ramme for verdiskapning. In B. T. K alsaas (Ed.), Lean construction : forstå og forbedre prosjektbasert produksjon 417-449, B ergen: Fagbokforlaget (2017)

2. B.T. Kalsaas, G. Hannås, G. Frislie, J. Skaar, Transformation from design-bid-build to design-build contracts in road construction, Proceedings of IGLC 1810 (2018)

3. W.A. Lichtig, Sutter health: Developing a contracting model to support lean project delivery. Lean construction journal 2(1):105-112 (2005)

4. G. Ballard, Should Project budgets be based on worth or cost. Paper presented at the International conference of the international group for lean construction (2012)

5. G.A. Howell, Meeting of DBIA Northern California. A presentation of "where LCI and DBIA agree and where we differ". Oakland, CA (2011)

6. U.O.K. N wajei, C. Bydall, Integrated project delivery (IPD) in Norwegian construction projects. Sharing of risk and opportunities aiming at better cooperation and project achievement. (Industrial Economics and Technology M anagement M asters), U niversity of A gder, Grimstad, N orway (2018)

7. P. Lahdenperä, Making sense of the multi-party contractual arrangements of project partnering, project alliancing and integrated project delivery, Construction Management and Economics 30(1):57-79 (2012).

8. D. Do, G. Ballard, \& I. D. Tommelein (2015). A n analysis of potential misalignments of commercial incentives in Integrated Project Delivery and Target $V$ alue Design. In Proceedings of the 23 rd Conference of the International Group for L ean Construction (pp. 277-286)

9. O. M atthews, G.A. Howell, Integrated project delivery an example of relational contracting, Lean construction journal 2(1):46-61 (2005) 
10. A merican Institute of A rchitects, Integrated Project Delivery - A n U pdated W orking Definition. In A IA National and A IA California Council Sacramento, CA , 18 (2014)

11. R. Ghassemi, B. B ecerik-Gerber, Transitioning to Integrated Project Delivery: Potential barriers and lessons learned, Lean Construction Journal (2011)

12. G. B allard, P. Reiser, The St. Olaf College Fieldhouse Project: A Case Study in Designing to Target Cost, In:, Bertelsen, S. \& Formoso, C.T,. Paper presented at the 12th annual conference of the International Group for L ean construction, Denmark, 3-5 (2004)

13. A merican Institute of A rchitects, Integrated Project Delivery: A Guide. In A merican Institute of A rchitects National and A IA California Council Sacramento, CA, 62 (2007)

14. A. Sayer, Method in social science: a realist approach ( 2 nd ed.). London: Routledge (1992)

15. R.K. Y in, Case study research:design and methods (3rd ed.). Thousand Oaks, California: Sage Publications (2003)

16. D.G. Reinertsen, Managing the design factory: a product developer's toolkit. $\mathrm{N}$ ew Y ork, USA : Free Press (1997)

17. K.M. Eisenhardt, A gency theory: A n assessment and review. A cademy of management review 14(1):57-74 (1989)

18. O.E. Williamson, Transaction-cost economics: the governance of contractual relations. The journal of L aw and Economics 22(2):233-261 (1979)

19. P. Schauwecker, (2012). Opportunismus im Exportgeschäft [Opportunism in the export business]. München: Oldenbourg.

20. C. Steinle, H. Schiele, T. Ernst, Information asymmetries as antecedents of opportunism in buyer-supplier relationships: Testing principal-agent theory, Journal of business-to-business marketing 21(2):123-140 (2014)

21. E. A nderson, Transaction costs as determinants of opportunism in integrated and independent sales forces, Journal of Economic Behavior \& Organization 9(3):247-264 (1988)

22. G. John, A n empirical investigation of some antecedents of opportunism in a marketing channel, Journal of marketing Research 278-289 (1984)

23. K.H. W athne, J.B. Heide, Opportunism in interfirm relationships: Forms, outcomes, and solutions, Journal of marketing 64(4):36-51 (2000)

24. C.S. Lai, S.S. Liu, C.F. Y ang, H.W. Lin, H.W. T sai, Governance mechanisms of opportunism: Integrating from transaction cost analysis and relational exchange theory. 台灣管理學刊, 5(1):1-23 (2005)

25. A. Rindfleisch, J.B. Heide, Transaction cost analysis: Past, present, and future applications. The Journal of Marketing 30-54 (1997)

26. O.E. W illiamson, The Economic Institutions of Capitalism: Firms, Markets, and Relational Contracting (1985)

27. O.E. W illiamson, Corporate finance and corporate governance, The journal of finance 43(3):567-591 (1988)

28. M. B ergen, S. Dutta, O.C. Walker J r, A gency relationships in marketing: A review of the implications and applications of agency and related theories. The Journal of Marketing 1-24 (1992) 
29. Y . Luo, Opportunism in inter-firm exchanges in emerging markets, Management and Organization Review 2(1):121-147 (2006)

30. S.E. M asten, Equity, opportunism, and the design of contractual relations, Journal of Institutional and Theoretical Economics (JITE)/Zeitschrift für die gesamte Staatswissenschaft 144(1):180-195 (1988)

31. T.J. M uris, Opportunistic behavior and the law of contracts. Minn. L. Rev., 65:521 (1981)

32. I.R. M acneil, Contracts: adjustment of long-term economic relations under classical, neoclassical, and relational contract law, Nw. UL Rev., 72:854 (1977)

33. A.R. Aslesen, R. Nordheim, B. Varegg, O. Lædre, IPD in Norway. Paper presented at the 26th A nnual Conference of the International Group for Lean Construction, Chennai, India (2018)

34. Tønsbergprosjektet, Integrated Project Delivery (IPD)- Presentation of SiV and the Tønsberg project (2017)

35. E.S. J on G resseth, Overview comparison of risk - IPD and NS 8405. M emorandum (2016)

36. H. Ashcraft, Integrated project delivery: The owner's perspective. San Francisco: Hanson Bridgett LLP (2013) 